\title{
Measuring the importance of health domains in psoriasis - discrete choice experiment versus rating scales
}

This article was published in the following Dove Press journal:

Patient Preference and Adherence

\section{Mandy Gutknecht ${ }^{\prime}$ \\ Marthe-Lisa \\ Schaarschmidt ${ }^{1,2}$ \\ Marion Danner ${ }^{3}$ \\ Christine Blome' \\ Matthias Augustin'}

'German Center for Health Services Research in Dermatology (CVderm), Institute for Health Services Research in Dermatology and Nursing (IVDP), University Medical Center HamburgEppendorf (UKE), Hamburg, Germany; ${ }^{2}$ Department of Dermatology, University Medical Center Mannheim, Heidelberg University, Mannheim, Germany; ${ }^{3}$ nstitute for Health Economics and Clinical Epidemiology (IGKE), University Hospital of Cologne, Cologne, Germany
Correspondence: Mandy Gutknecht German Center for Health Services Research in Dermatology (CVderm), Institute for Health Services Research in Dermatology and Nursing (IVDP), University Medical Center HamburgEppendorf (UKE), Martinistr 52, D-20246 Hamburg, Germany Tel +49 4074 I 052 I 29

Fax +49 40 74I 040 I60

Email m.gutknecht@uke.de
Background: Psoriasis affects different aspects of health-related quality of life (eg, physical, psychological, and social impairments); these health domains can be of different importance for patients. The importance of domains can be measured with the Patient Benefit Index (PBI). This questionnaire weights the achievement of treatment goals by Likert scales (0, "not important at all" to 4, "very important") using the Patient Needs Questionnaire (PNQ). Treatment goals assessed with the PBI have been assigned to five health domains; the importance of each domain can be calculated as the average importance of the respective treatment goals. In this study, the PBI approach of deriving importance weights is contrasted to a discrete choice experiment (DCE), in order to determine the importance of health domains in psoriasis, and to find if the resulting weights will differ when derived from these two methods.

Methods: Adult patients with psoriasis completed both questionnaires (PNQ, DCE). The PBI domains were used as attributes in the DCE with the levels "did not help at all", "helped moderately", and "helped a lot".

Results: Using DCE, "improving physical functioning" was the most important health domain, followed by "improving psychological well-being". Using PNQ, these domains were ranked in position two and three following "strengthening confidence in the therapy and in a possible healing". The latter was least important using DCE. The only agreement of ranking was shown in "reducing impairments due to therapy" (position four). "Improving social functioning" was ranked in position three (DCE) and five (PNQ).

Conclusion: Health domains have different importance to patients with psoriasis. Using PNQ or DCE to determine the importance of domains results in markedly different rankings; both approaches can thus not be considered equivalent. However, in this study, importance was assessed at the domain level in DCE and at the single item level in PNQ, which may have added to the differences.

Keywords: conjoint analysis, Patient Benefit Index, patient-reported outcomes, preferences

\section{Introduction}

Psoriasis is one of the most prevalent chronic diseases in dermatology worldwide. ${ }^{1}$ In addition to topical therapy and phototherapy, various systemic treatments are available, including traditional systemic therapies as well as biologicals. ${ }^{2}$ As skin disease affects all aspects of quality of life, including physical, psychological, social, sexual, and occupational elements, ${ }^{3,4}$ several treatment goals representing different health domains need to be addressed to define the patient-relevant benefit of antipsoriatic therapies. Thereby, health domains may be of different importance for 
the patient. The Patient Benefit Index (PBI) is a diseasespecific patient-reported outcomes instrument measuring the treatment benefit while considering the importance of patients' treatment goals.

The first PBI version, which has been validated for skin diseases including psoriasis, ${ }^{5}$ contains 23 patientrelevant treatment goals. In the first part (Patient Needs Questionnaire [PNQ]), patients are asked before treatment to rate the importance of each goal on a five-step Likert scale from 0 (not important at all) to 4 (very important). In the second part to be completed during or after therapy (Patient Benefit Questionnaire [PBQ]), patients rate the extent to which the current therapy has helped attain these goals, scaled from 0 (treatment did not help at all) to 4 (treatment has helped very much). As an alternative, patients can select "does not apply to me" for any item in both questionnaires. The importance-weighted PBI global score is calculated by dividing the PNQ rating of one goal by the sum of all PNQ ratings and multiplying it with the respective rating on the $\mathrm{PBQ}$. By summing up the resulting products, the PBI can obtain values from 0 (no benefit) to 4 (maximum benefit). ${ }^{5,6}$

In previous research, the 23 treatment goals implemented in the first version of the PBI have been empirically assigned to five dimensions (reducing social impairments, reducing psychological impairments, reducing impairments due to therapy, reducing physical impairments, having confidence in healing), using exploratory factor analysis. ${ }^{6}$ For each dimension (hereafter health domain), benefit subscales of the respective items provide information on patient benefit in different areas. ${ }^{6}$ The importance of the five health domains is derived by averaging the importance ratings of the respective treatment goals.

However, PBI is not the only method for the determination of importance. The preference-based method of discrete choice experiment (DCE) can also be applied to capture the relative importance that patients place on different health domains. Thus, the question arises to which extent the importance of health domains may differ if determined with the PBI Likert scales or with the preference-based DCE.

DCE belongs to the group of conjoint analytic preference elicitation methods. ${ }^{7-9}$ It elicits preferences and trade-offs that individuals are willing to make between attributes by asking respondents to choose between goods or services described by their attributes. ${ }^{10}$ The method is based on the premise that any good or service can be described by its characteristics (attributes) and that the extent to which an individual values a good or service depends on the levels of these attributes. ${ }^{11}$ According to best practice standards, ${ }^{12}$ patient-relevant attributes of a treatment (eg, delivery method) and attribute levels (eg, ointment, tablets, and injections) have to be identified. Afterward, the attributes are combined to define hypothetical services or goods and the patient is asked to repeatedly choose the preferred one out of the presented options. ${ }^{13}$

DCE has already been successfully applied in psoriasis research. A recently conducted systematic literature review ${ }^{14}$ including articles published and available until 2014 refers to eight publications in this field; up to February 2017, further studies using this method have been published. ${ }^{15-17}$ All studies focused on patients' preferences for psoriasis treatments while using on the one hand outcome attributes such as probability of benefit, duration of benefit, and risk of adverse events and on the other hand, process attributes like treatment location, frequency, and duration. However, none of these studies on psoriasis used DCE to assess the relevance of health domains of a disease-specific patient-reported outcome instrument like the PBI. However, in other diseases such as cancer and obesity, few studies ${ }^{18-20}$ have investigated a similar research question; results indicated the need to consider the relative importance that patients assign to different health domains. In patients with psoriasis the relative importance of certain health domains implemented in a patient-reported outcomes instrument may also differ from one to another, as the disease is not only associated with physical discomfort, but also with a multitude of psychological and social impairments, especially in the presence of highly visible areas of the skin such as the face and hands. ${ }^{21}$

Therefore, the objective of the presented survey was to apply a DCE to obtain preference weights for the domains of the PBI summarizing patient-relevant treatment goals in psoriasis and to compare these weights to those resulting from the weighting procedure of the PBI, which is based on Likert scales (PNQ).

\section{Methods}

\section{Study design}

This preference elicitation study comprised two visits for each included participant in the outpatient clinic of a university medical center. Individuals aged $\geq 18$ years with a physician-confirmed diagnosis of plaque-type psoriasis who started a new anti-psoriatic therapy and who were cognitively able to fill out the questionnaires were eligible. Patients starting treatment completed a survey at baseline and at follow-up (scheduled 12 weeks later). This non-interventional study was approved by the local ethical review committee in 
Hamburg (Ethik-Kommission der Ärztekammer Hamburg; reference number: PV5182).

\section{Data collection}

At both visits, patients were asked about their sociodemographic and disease-related characteristics, previous and current treatments, their satisfaction with their last therapy using the Treatment Satisfaction Questionnaire for Medication (TSQM 1.4), ${ }^{22}$ and their subjective perception of the burden of their skin disease by three Likert-scaled global questions. Additionally, at baseline, the PNQ and a DCE survey were provided to the patients. The order of methods (PNQ, DCE) was varied between patients to enable control of possible order effects. Following each method, patients answered standardized questions concerning the easiness to complete the respective questionnaire part. At the follow-up visit, the PBQ was assessed.

The survey was conducted using standardized computerized questionnaires. After signing a written informed consent, each patient answered the computerized survey and assistance was provided if necessary during the survey. To avoid missing values, consecutive pages could only be filled out if all questions on the previous page had been completely answered.

In addition, disease severity (Psoriasis Area and Severity Index [PASI]) and patient's skin-related quality of life (Dermatology Life Quality Index [DLQI]) were documented for each patient at both visits.

\section{Selection of attributes and levels}

While the PNQ asks patients to rate all 23 goals regarding their importance, the inclusion of all 23 goals as single attributes was not possible in a DCE. Since many of the 23 goals are highly likely empirically associated (eg, to feel less depressed and to experience a greater enjoyment of life) or are based on overlapping concepts, the five overarching domains of the PBI (Table 1) were used as attributes, which were presented to the patients as comprehensively as possible ensured by pilot testing; and the respective goals were used to explain these attributes to the patients (Figure 1). Corresponding to the possible answers in the PBQ, the attribute levels were specified as "did not help at all", "helped moderately", and "helped a lot". The levels "somewhat" and "quite" were eliminated in order to reduce the complexity of the DCE tasks.

\section{Development of the DCE}

At the beginning of the DCE questionnaire, each respondent was instructed to imagine two patients (A and B) with the same severity of psoriasis as the respondent, both receiving
Table I Patient-relevant treatment goals and domains of the PBI

\begin{tabular}{|c|c|}
\hline PBI & $\begin{array}{l}\text { Corresponding patient-relevant treatment } \\
\text { goals }\end{array}$ \\
\hline $\begin{array}{l}\text { educing social } \\
\text { ppairments }\end{array}$ & $\begin{array}{l}\text { To be less of a burden to relatives and friends } \\
\text { To be able to lead a normal working life } \\
\text { To be able to have more contact with other people } \\
\text { To be comfortable showing yourself more in public } \\
\text { To be less burdened in your partnership } \\
\text { To be able to have a normal sex life }\end{array}$ \\
\hline $\begin{array}{l}\text { Reducing } \\
\text { psychological } \\
\text { impairments }\end{array}$ & $\begin{array}{l}\text { To feel less depressed } \\
\text { To experience a greater enjoyme } \\
\text { To be able to lead a normal every } \\
\text { To be more productive in everyd } \\
\text { To be able to engage in normal le }\end{array}$ \\
\hline $\begin{array}{l}\text { Reducing } \\
\text { impairments due } \\
\text { to therapy }\end{array}$ & $\begin{array}{l}\text { To be less dependent on doctor and clinic visits } \\
\text { To need less time for daily treatment } \\
\text { To have fewer out-of-pocket treatment expenses } \\
\text { To have fewer side effects }\end{array}$ \\
\hline $\begin{array}{l}\text { Reducing physical } \\
\text { impairments }\end{array}$ & $\begin{array}{l}\text { To be free of pain } \\
\text { To be free of itching } \\
\text { To no longer have burning sensations on your skin } \\
\text { To be healed of all skin defects } \\
\text { To be able to sleep better }\end{array}$ \\
\hline $\begin{array}{l}\text { Having confidence } \\
\text { in healing }\end{array}$ & $\begin{array}{l}\text { To have no fear that the disease will become worse } \\
\text { To find a clear diagnosis and therapy } \\
\text { To have confidence in the therapy }\end{array}$ \\
\hline
\end{tabular}

Note: Reprinted by permission from Springer Nature: Arch Dermatol Res. Blome C Augustin M, Behechtnejad J, Rustenbach SJ. Dimensions of patient needs in dermatology: subscales of the patient benefit index. Copyright @) 2010, Springer Nature (201 I). http://www.springer.com/medicine/dermatology/journal/403. ${ }^{6}$ Abbreviation: PBI, Patient Benefit Index.

a new treatment. Next, each respondent completed 12 choice tasks, each presenting a choice between two hypothetical outcome profiles created by combining the different levels of each attribute reported by patient A and patient B under treatment. For each task, respondents were asked to choose the scenario they considered preferable. Profiles were generated by using conjoint analytic software Sawtooth, version 8.4.8 (Sawtooth Software, Inc., Orem, Utah, USA) to design a balanced and efficient set of choice tasks. An example of a choice task is presented in Figure 1. Of the $243(3 \times 3 \times 3 \times 3 \times 3)$ possible profiles, 12 pairs of scenarios were constructed for each respondent by the software that followed principles of the balanced overlap approach (randomized design) ${ }^{23}$ Additionally, the DCE was designed including two fixed choice tasks to test for the ability of the patient to complete the DCE questionnaire. In one fixed task, the answers of patient A were clearly preferable to the answers of patient $B$ and in the other fixed task the treatment of patient B was obviously more helpful than the treatment of patient $\mathrm{A}$. If patients failed the fixed tasks, they were excluded from the final analyses.

Sample size calculation for $\mathrm{DCE}^{24}$ suggested the need to survey at least 125 participants, given the use of 12 discrete 


\begin{tabular}{|c|c|c|}
\hline Has the treatment helped you ... & $\begin{array}{c}\text { Patient A } \\
\text { said }\end{array}$ & $\begin{array}{c}\text { Patient B } \\
\text { said }\end{array}$ \\
\hline $\begin{array}{l}\text {... to improve your social functioning? } \\
\text { ie, more contact with others, a normal working life, be less of a burden } \\
\text { and friends, be comfortable showing yourself more in public, be less bu } \\
\text { in the partnership, and a normal sex life }\end{array}$ & Moderately & Not at all \\
\hline $\begin{array}{l}\text {... to improve your psychological well-being? } \\
\text { ie, feel less depressed, a greater enjoyment of life, more productive in } \\
\text { life, to engage in normal leisure activities, and a normal everyday life }\end{array}$ & Not at all & A lot \\
\hline $\begin{array}{l}\text {... to reduce your impairments due to therapy? } \\
\text { ie, fewer side effects, less time for daily treatment, less dependent on d } \\
\text { and clinic visits, and fewer out-of-pocket treatment expenses }\end{array}$ & Not at all & Moderately \\
\hline $\begin{array}{l}\text {... to improve your physical functioning? } \\
\text { ie, be free of pain, no burning sensations on the skin, free of itching, be } \\
\text { of all skin defects, and be able to sleep better }\end{array}$ & Not at all & Not at all \\
\hline $\begin{array}{l}\text {... to strengthen confidence in the therapy and in a possible healing? } \\
\text { ie, confidence in the therapy, find a clear diagnosis and therapy, and } \\
\text { no fear that the disease will become worse }\end{array}$ & A lot & Moderately \\
\hline In your opinion, for which patient has the treatment been more helpful? & & \\
\hline
\end{tabular}

Figure I Example of a pairwise presented choice task generated by Sawtooth Software.

choice tasks, two alternatives per choice task, and a maximum of three levels within one attribute.

\section{Statistical analyses}

In the descriptive analyses, patient characteristics were presented as absolute and percentage frequencies for categorical data as well as means and standard deviation for continuous variables.

The importance weight of a health domain obtained through the PNQ was calculated using two steps. First, according to the PBI formula described above, for each goal within the PNQ the importance was derived from the ratings between "not at all important" $(0)$ and "very important" (4) divided by the sum of all importance ratings of the respective patient. Thereby, the response "does not apply to me" was coded as zero (0). Second, by averaging the importance of treatment goals within one domain and dividing it with the sum of mean importance weights of all domains, the aggregated importance for each of the five domains was derived:

$$
\begin{aligned}
& \text { Importance weight of a goal } \\
& =\frac{\text { Rating of the treatment goal between } 0 \text { and } 4}{\text { Sum of all ratings }}
\end{aligned}
$$

Importance weight of a domain

$$
=\frac{\text { Mean importance weight of goals within the domain }}{\text { Sum of mean importance weights of all domains }}
$$

For the calculation of relative importance weights for the attributes of each individual patient generated by DCE, the hierarchical Bayes (HB) module of Sawtooth Software ${ }^{25}$ was used. The HB model applied in Sawtooth Software uses data from the DCE to estimate the zero-centered numerical values (part-worth utility values) that each respondent attaches to the different levels of attributes. ${ }^{26}$ Detailed information on the HB estimation is available in a technical paper of Sawtooth Software. ${ }^{26}$ Within each attribute, the utility values sum to zero. From these part-worth utilities, one can characterize the relative importance of each attribute by finding the percentage of each utility range (highest minus the lowest part-worth utility) of one attribute on the sum of all utility ranges across attributes. ${ }^{24}$ The higher the range of part-worth utilities, the higher the relative importance of an attribute. As recommended, ${ }^{24}$ relative importance weights for respondents were calculated individually and then averaged across all participants.

Individual importance weights obtained through PNQ and preference weights obtained through DCE were 
arithmetically averaged and rank ordered for comparison between the methods. To test whether there was a statistically significant difference between weights of PBI domains as calculated with DCE and PNQ and concerning the easiness to complete between the methods, $t$-test for paired samples and McNemar test in the existence of dichotomous variables were performed using SPSS Statistics 23 (IBM Corporation, Armonk, NY, USA) for Microsoft Windows. Furthermore, analyses included the use of single measure intraclass correlation coefficients and Pearson correlation coefficients to compare observed weightings of the two measures (DCE and PNQ), which was additionally visualized by scatterplots including regression line. Additionally, subgroup analyses on patients who did not pass the fixed choice tasks of the DCE were conducted to determine characteristics of patients who might not be able to complete the DCE.

\section{Results Study group}

Of the 164 patients that were contacted between February 2016 and January 2017, 150 patients took part in the survey. Fourteen patients were not willing to participate due to lack of time or interest. As the survey was computer-based and each page required answering all questions, there were no missing data in the PNQ and DCE. However, one patient left the survey incomplete during the DCE saying that the survey was too long. In addition, 20 patients who did not pass the fixed choice tasks of the DCE were excluded for the calculation of importance weights. In total, data of 129 patients were available for analysis.

Mean age was $44.7 \pm 14.0$ years (median: 46 , range: 19-78); $59.7 \%$ were male; $6.2 \%$ had a nationality other than German; and $45.0 \%$ had a higher education entrance qualification. Sixty-seven percent of patients suffered from mild psoriasis (PASI $\leq 10$ ) and $23 \%$ from moderate-tosevere psoriasis (PASI > 10). Mean PASI score was 8.0 \pm 8.4 (median: 6, range: $0-49, \mathrm{n}=12$ missing values) and the mean impairment in quality of life (DLQI; $0-30=$ maximum impairment) was 9.6 \pm 6.8 (median: 8 , range: $0-26, \mathrm{n}=12$ missing values). Patients most frequently started with a systemic treatment (98.4\%), including biological treatment (74.4\%). One patient started with a topical treatment, and another received blinded study medication. On average, disease duration was 18.7 \pm 13.6 years (median: 17 , range: $0-54$ ).

\section{Importance weights}

Average part-worth utilities (zero-centered differences) resulting from $\mathrm{HB}$ estimation for the attribute levels included

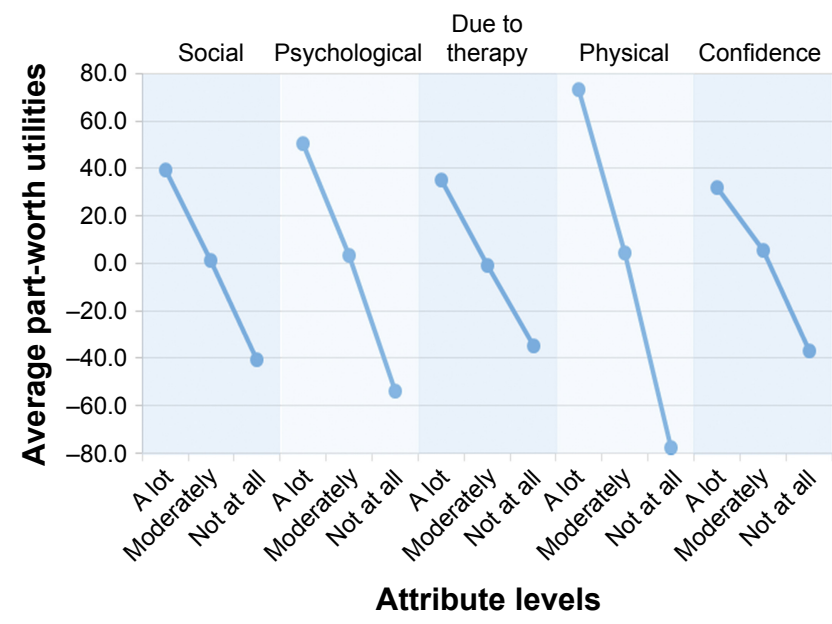

Figure 2 Average part-worth utilities for the attribute levels in the discrete choice experiment (DCE).

in the DCE are presented in Figure 2. The levels "a lot", "moderately", and "not at all" were all ordered across attributes as expected.

Using the PNQ, the five treatment goals with the highest ranks were "to be healed of all skin defects", "to be free of itching", "to have no fear that the disease will become worse", "to find a clear diagnosis and therapy", and "to have confidence in the therapy". The first two goals were part of the five treatment goals included in the attribute "improving physical functioning"; the other three goals were summarized by the attribute "strengthening confidence in the therapy and in a possible healing". Accordingly, "strengthening confidence in the therapy and in a possible healing" was ranked as most important followed by "improving physical functioning". The treatment goals "to be less of a burden to relatives and friends", "to have fewer out-of-pocket treatment expenses", and "to be able to sleep better" were ranked as least important.

Importance weights and rank order of attributes (health domains) obtained through DCE and PNQ are shown in Table 2 (weights sum up to one for each method).

The analysis of the DCE and PNQ resulted in a different ranking of attributes. Using DCE, the first most important attribute was "improving physical functioning," followed by "improving psychological well-being". Using the PNQ, these attributes were ranked in position two and three, while "strengthening confidence in the therapy and in a possible healing" was ranked as the most important. In contrast, the latter was ranked as least important using the DCE. Depending on the applied method, "improving social functioning" was ranked in position three (DCE) or five (PNQ), whereas the only agreement of the rank order could be observed in the attribute "reducing impairments due to therapy" (position four). 
Table 2 Comparison of importance weights for PBI domains (= attributes) obtained through DCE vs PNQ (weights sum up to one for each method; $n=129$ )

\begin{tabular}{|c|c|c|c|c|c|c|c|c|c|c|c|c|c|}
\hline \multirow[t]{2}{*}{ PBI domain } & \multicolumn{5}{|l|}{ DCE } & \multicolumn{5}{|l|}{ PNQ } & \multirow{2}{*}{$\begin{array}{l}\text { DCE vs } \\
\text { PNQ } \\
\text {-value }^{a}\end{array}$} & \multicolumn{2}{|c|}{$\begin{array}{l}\text { ICC - single } \\
\text { measure } \\
\text { intraclass } \\
\text { correlation }\end{array}$} \\
\hline & Mean & $\begin{array}{l}\text { Rank } \\
\text { order }\end{array}$ & SD & Median & Range & Mean & $\begin{array}{l}\text { Rank } \\
\text { order }\end{array}$ & SD & Median & Range & & ICC & $p$-value \\
\hline $\begin{array}{l}\text { Improving social } \\
\text { functioning }\end{array}$ & 0.166 & 3 & 0.06 & 0.166 & $0.04-0.37$ & 0.166 & 5 & 0.06 & 0.180 & $0.00-0.31$ & 0.940 & 0.176 & 0.023 \\
\hline $\begin{array}{l}\text { Improving psychological } \\
\text { well-being }\end{array}$ & 0.217 & 2 & 0.08 & 0.209 & $0.02-0.49$ & 0.194 & 3 & 0.06 & 0.202 & $0.00-0.36$ & 0.005 & 0.196 & 0.013 \\
\hline $\begin{array}{l}\text { Reducing impairments } \\
\text { due to therapy }\end{array}$ & 0.153 & 4 & 0.07 & 0.141 & $0.04-0.43$ & 0.175 & 4 & 0.06 & 0.183 & $0.00-0.39$ & 0.005 & 0.139 & 0.058 \\
\hline $\begin{array}{l}\text { Improving physical } \\
\text { functioning }\end{array}$ & 0.312 & I & 0.12 & 0.305 & $0.04-0.61$ & 0.222 & 2 & 0.05 & 0.218 & $0.08-0.47$ & $<0.001$ & 0.166 & 0.029 \\
\hline $\begin{array}{l}\text { Strengthening confidence } \\
\text { in the therapy and in a } \\
\text { possible healing }\end{array}$ & 0.152 & 5 & 0.08 & 0.140 & $0.01-0.59$ & 0.243 & I & 0.08 & 0.231 & $0.00-0.65$ & $<0.001$ & 0.075 & 0.197 \\
\hline
\end{tabular}

Note: ${ }^{\text {at}}$-test for paired samples.

Abbreviations: PBI, Patient Benefit Index; DCE, discrete choice experiment; PNQ, Patient Needs Questionnaire; SD, standard deviation; ICC, intraclass correlation coefficient.

Except for the attribute "improving social functioning", mean importance weights obtained through DCE and PNQ were significantly different (Table 2), which is also demonstrated in Figure 3. Using single measure intraclass correlation, no concordance was found between the overall attributes obtained through DCE and PNQ (Table 2). Pearson correlation confirmed weak associations between the weightings of "improving social functioning", "improving psychological well-being", and "improving physical functioning", which were also observed in Figure 4.

\section{Comparison of method's easiness to complete}

After completing the questionnaire, patients answered three questions concerning the method's easiness to complete (Table S1). When asked whether the instruction was comprehensible (response options "yes" or "no"), the majority of patients answered "yes" with regards to both methods ( $p=0.453)$. Significantly more patients assessed the DCE as "too long" as compared to the PNQ $(p<0.001)$. Participants rated the PNQ as easier than the DCE $(p<0.001)$ on a scale from 0 (not at all difficult) to 10 (very difficult).

\section{Subgroup analyses}

Between included patients $(n=129)$ and patients excluded due to failing the fixed choice tasks in the DCE $(n=20)$, there were no significant differences regarding age (mean: 44.7 vs 45.8 years; $p=0.745$ ), gender (male: $59.7 \%$ vs $70.0 \%$; $p=0.379$ ), nationality (German: $93.8 \%$ vs $100.0 \% ; p=0.252$ ), household income ( $<€ 3,000: 54.8 \%$ vs $77.8 \%$; $p=0.066)$, or school degree (higher education: $46.4 \%$ vs $44.4 \% ; p=0.876$ ). Additionally, the method order was not significantly different

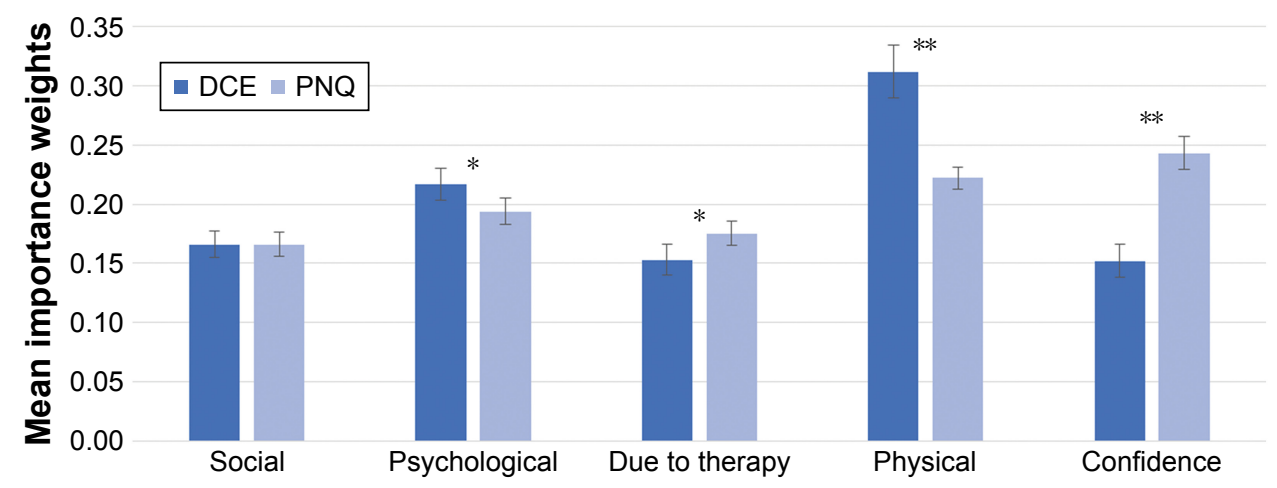

Figure 3 Comparison of importance weights for PBI domains obtained through discrete choice experiment (DCE) versus Patient Needs Questionnaire (PNQ) ( $\mathrm{n}=$ I29). Notes: ${ }^{*} p<0.05$, significant difference between importance weights; ${ }^{* *} p<0.00$ I, high significant difference between importance weights. 

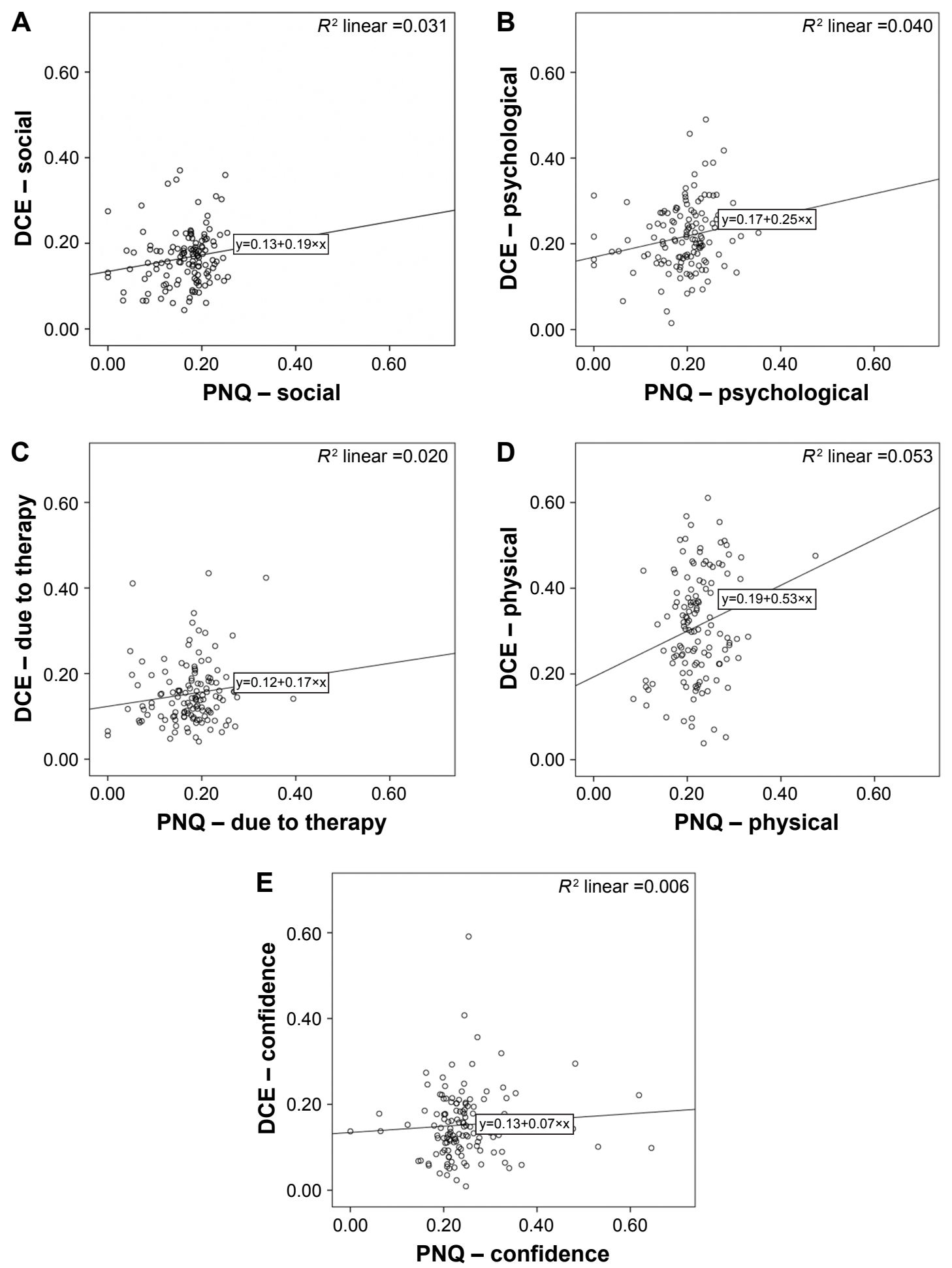

Figure 4 Scatterplots including regression line for comparison of importance weights for Patient Benefit Index domains between the two measures, discrete choice experiment (DCE) versus Patient Needs Questionnaire (PNQ) ( $n=129)$.

Notes: Figure parts (A to E) present comparisons for the five different health domains: (A) improving social functioning, (B) improving psychological well-being, (C) reducing impairments due to therapy, (D) improving physical functioning, and (E) strengthening confidence in the therapy and in a possible healing.

between included and excluded patients (first PNQ, then DCE: $50.4 \%$ vs $55.0 \% ; p=0.701)$. However, significantly more excluded patients assessed the DCE as "too long" ("yes": $45.0 \%$ vs $75.0 \% ; p=0.012$ ). In both groups, the DCE instruction was predominantly rated comprehensible $(96.1 \%$ vs $100 \% ; p=0.370$ ) and there was no significant difference concerning the question how difficult the DCE was to answer (3.05 vs $3.15 ; p=0.849)$. 


\section{Discussion}

In this study, we estimated the importance of five health domains in patients with psoriasis, which stem from exploratory factor analyses on the 23 treatment goals ${ }^{6}$ implemented in the patient-reported outcomes instrument PBI. Our results provide clear evidence that patients with psoriasis assign different importance to health domains, which should be considered in the benefit evaluation of anti-psoriatic therapies. This is consistent with the findings of Hauber et al, ${ }^{20}$ Osoba et al, ${ }^{18}$ and Johnson et al ${ }^{19}$ who also found that specific health domains in other patient-reported outcomes instruments, more precisely in different health-related quality of life questionnaires, are of varying importance to patients by using a DCE in populations with other diseases. However, in our study, we especially focused on the difference of importance weights of health domains depending on the applied method in patients with psoriasis. Thereby, we could show that depending on the method to weight health domains, either at the domain level in DCE or at the single item level in the PNQ, importance differed strongly. This resulted in a major difference of the ranking of "strengthening confidence in the therapy and in a possible healing" (first position via PNQ versus last position via DCE).

Several reasons may explain this finding. First, with the DCE, direct trade-offs between outcomes of health domains could be considered. In contrast with the PNQ, the importance of a health domain was based on the average of individual ratings for the respective treatment goals belonging to this domain, using the five-step Likert-scales (0, "not important at all" to 4, "very important"). Thereby, patients can assign the highest value (4) to each treatment goal. They are not forced to decide which goal is more preferred in direct comparison to another one. However, no ceiling effects were found, except in one patient.

Second, in the DCE we had to assume that attributes corresponding to the PBI domains are fully reflected by the associated treatment goals. To ensure that patients completing the DCE part had the same understanding of each domain, attributes were described by their respective treatment goals of the PNQ (Figure 1). Nevertheless, not all patients may have fully read the descriptions. The domain label that has been added to the single goals in the DCE may have connotations beyond the context of the single goals. For example, the attribute labeled "strengthening confidence in the therapy and in a possible healing" may suggest lower treatment efficacy beyond what the subordinate treatment goals described with wordings like "to have no fear that disease will become worse" and "to find a clear diagnosis and therapy". Consequently, in the DCE, this attribute did not appear to have the same chance of being equally highly weighted as with the weighting procedure of the PNQ. Previous research in psoriasis patients, ${ }^{6,27}$ who completed the PNQ, confirms the importance of treatment goals from the health domain "strengthening confidence in the therapy and in a possible healing." Thus, differences in importance weights and rank orders between the methods cannot only be explained by the difference of the respective weighting procedures but rather by the labeling of attributes.

Third, selected levels in the DCE were not comparable with the treatment goals in the PNQ because asking patients about their preferences, for example between "to have no fear that the disease will become worse" and "to have confidence in the therapy", was not reasonable due to overlapping outcomes. Thus, we could not make use of the levels in the DCE.

Fourth, an important requirement in conducting a DCE is to avoid dependencies between attributes. ${ }^{28}$ In the pretests, participants mentioned for example that they could not imagine having an improvement in physical impairments without any reduction of psychological impairments. For this reason, we followed the example of Hauber et $\mathrm{al}^{20}$ who transformed the IWQOL-Lite (a validated instrument to assess healthrelated quality of life in obese people) into a choice-format conjoint survey to reflect the relative importance that overweight and obese people place on the domains included in this instrument. In the pretests, many participants also rejected the notion that certain outcomes could apply to them. This is why we did not ask patients to choose a set of outcomes they preferred for themselves but to imagine patient $\mathrm{A}$ and B who had the same severity of psoriasis as themselves, and to decide which hypothetical scenario was more preferable in their opinion. As participants were thus not asked which hypothetical scenario they would prefer for themselves in the future, the results of the presented DCE might be interpreted as patient's evaluation of relative importance of health domains in general rather than as individual preferences. This limitation was also discussed in Hauber et al. ${ }^{20}$

As a further limitation, our study was conducted exclusively in a university medical center. Most participants received biologics (74.4\%), which is because patients must remain under observation after the first application of biologics and were therefore preferentially asked to participate. However, the risk of patient selection could be accepted as the primary objective of our study was not to draw a conclusion about the importance of health domains in different psoriasis patients but rather to compare the importance of health domains depending on the used method. Finally, due to the complexity of the 
applied methods, patients were allowed to ask comprehension questions during the survey, which may have affected the study results; however, this was important in order to avoid patient exclusion due to implausible statements.

\section{Conclusion}

With the PBI, a validated questionnaire for the evaluation of patient-reported treatment benefit including a weighting on the level of treatment goals (PNQ) is available. In previous research, the treatment goals assessed with the PBI have been assigned to five health domains, and the importance of each health domain can be calculated as the average importance of the respective treatment goal items. In this study, the PBI approach of deriving importance weights was contrasted to the more elaborate approach of DCE, in order to determine the importance of different health domains in psoriasis, and to find if and how importance will differ when derived from these two methods.

Using PNQ or DCE to determine the importance of health domains results in markedly different weights; both approaches can thus not be considered equivalent. However, in this study, health domains were assessed at the domain level in DCE and at the single item level in the PNQ, which may have added to the differences in domain weights.

Independently of the method, we found that health domains have different importance to patients with psoriasis, which should be considered in the benefit evaluation of antipsoriatic therapies. Results may also be relevant in case of using other patient-reported outcomes instruments commonly applied in psoriasis research, especially in quality of life measures integrating different health domains (eg, the DLQI or the Psoriasis Disability Index, or in case of measuring the general health-related quality of life the Short Form 36 or EuroQoL 5D). Thereby, it needs to be taken into account which method is the most appropriate to weight health domains. Depending on the overall objective, one method might be more preferable or feasible than the other.

\section{Acknowledgments}

We thank the team at the Psoriasis Clinic, University Medical Center Hamburg-Eppendorf (Hamburg, Germany), for their support in patients' recruitment and Mario Gehoff, Sara Tiedemann, and Pia Dahlhoff for copyediting this manuscript. We also thank all the patients for their participation.

\section{Disclosure}

M Gutknecht received financial support for participation in conferences from AbbVie and obtained honoraria from Novartis. ML Schaarschmidt conducted clinical trials for
AbbVie, Boehringer Ingelheim, Celgene, Eli Lilly, JanssenCilag, Merck, Novartis, and UCB Pharma; obtained honoraria from Janssen-Cilag; and received financial support for participation in conferences from AbbVie, ALK-Abello, Biogen Inc, Janssen-Cilag, and MSD. C Blome has received speaker honoraria, research grants, awards, and/or travel expenses from Celgene, Janssen-Cilag, Kreussler, Lilly, Mapi Group, Medi, Stiefel Laboratories, and Urgo. M Augustin has served as consultant and/or paid speaker for and/or has received research grants and/or honoraria for consulting and/or scientific lectures for and/or got travel expenses reimbursed and/or participated in clinical trials sponsored by companies that manufacture drugs used for the treatment of psoriasis including AbbVie, Almirall, Amgen, Biogen Idec, Boehringer Ingelheim, Celgene, Centocor, Eli Lilly, Galderma, Janssen-Cilag, Leo, Medac, MSD, Mundipharma, Novartis, Pfizer, Sandoz, and Xenoport. M Danner reports no conflicts of interest in this work.

\section{References}

1. Parisi R, Symmons DPM, Griffiths CEM, Ashcroft DM. Global epidemiology of psoriasis: a systematic review of incidence and prevalence. J Invest Dermatol. 2013;133(2):377-385.

2. Nast A, Gisondi P, Ormerod AD, et al. European S3-guidelines on the systemic treatment of psoriasis vulgaris - update 2015 - short version - EDF in cooperation with EADV and IPC. J Eur Acad Dermatol Venereol. 2015;29(12):2277-2294.

3. Stern RS, Nijsten T, Feldman SR, Margolis DJ, Rolstad T. Psoriasis is common, carries a substantial burden even when not extensive, and is associated with widespread treatment dissatisfaction. J Investig Dermatol Symp Proc. 2004;9(2):136-139.

4. Kimball AB, Jacobson C, Weiss S, Vreeland MG, Wu Y. The psychosocial burden of psoriasis. Am J Clin Dermatol. 2005;6(6):383-392.

5. Augustin M, Radtke MA, Zschocke I, et al. The patient benefit index: a novel approach in patient-defined outcomes measurement for skin diseases. Arch Dermatol Res. 2009;301(8):561-571.

6. Blome C, Augustin M, Behechtnejad J, Rustenbach SJ. Dimensions of patient needs in dermatology: subscales of the patient benefit index. Arch Dermatol Res. 2011;303(1):11-17.

7. Bridges JFP, Kinter ET, Kidane L, Heinzen RR, McCormick C. Things are looking up since we started listening to patients: trends in the application of conjoint analysis in health 1982-2007. Patient. 2008;1(4):273-282.

8. Lancaster KJ. A new approach to consumer theory. J Political Econ. 1966;74(2):132-157.

9. McFadden D. Conditional logit analysis of qualitative choice behavior. In: Zarembka P, editor. Frontiers in Econometrics. New York: Academic Press; 1974:105-142.

10. Lancsar E, Louviere J. Conducting discrete choice experiments to inform healthcare decision making: a user's guide. Pharmacoeconomics. 2008;26(8):661-677.

11. Ryan M. Using conjoint analysis to elicit preferences for health care. BMJ. 2000;320(7248):1530-1533.

12. Bridges JFP, Hauber AB, Marshall D, et al. Conjoint analysis applications in health - a checklist: a report of the ISPOR Good Research Practices for Conjoint Analysis Task Force. Value Health. 2011;14(4):403-413.

13. Muhlbacher AC, Stoll M, Mahlich J, Nubling M. Patient preferences for HIV/AIDS therapy - a discrete choice experiment. Health Econ Rev. 2013;3(1):14. 
14. Gutknecht M, Schaarschmidt ML, Herrlein O, Augustin M. A systematic review on methods used to evaluate patient preferences in psoriasis treatments. J Eur Acad Dermatol Venerol. 2016;30(9):1454-1464.

15. Gonzalez JM, Johnson FR, McAteer H, Posner J, Mughal F. Comparing preferences for outcomes of psoriasis treatments among patients and dermatologists in the U.K.: results from a discrete-choice experiment. Br J Dermatol. 2016;176(3):777-785.

16. Kromer C, Schaarschmidt ML, Schmieder A, Herr R, Goerdt S, Peitsch WK. Patient preferences for treatment of psoriasis with biologicals: a discrete choice experiment. PLoS One. 2015;10(6): e0129120.

17. Eliasson L, Bewley AP, Mughal F, et al. Evaluation of psoriasis patients' attitudes toward benefit-risk and therapeutic trade-offs in their choice of treatments. Patient Prefer Adherence. 2017;11:353-362.

18. Osoba D, Hsu MA, Copley-Merriman C, et al. Stated preferences of patients with cancer for health-related quality-of-life (HRQOL) domains during treatment. Qual Life Res. 2006;15(2):273-283.

19. Johnson FR, Hauber AB, Osoba D, Hsu MA, Coombs J, CopleyMerriman C. Are chemotherapy patients' HRQoL importance weights consistent with linear scoring rules? A stated-choice approach. Qual Life Res. 2006;15(2):285-298.

20. Hauber AB, Mohamed AF, Johnson FR, Oyelowo O, Curtis BH, Coon C. Estimating importance weights for the IWQOL-Lite using conjoint analysis. Qual Life Res. 2010;19(5):701-709.

21. World Health Organization (WHO). Global report on psoriasis. Available from: http://apps.who.int/iris/bitstream/10665/204417/1/9789241 565189_eng.pdf. Accessed July 12, 2017.
22. Atkinson MJ, Sinha A, Hass SL, et al. Validation of a general measure of treatment satisfaction, the Treatment Satisfaction Questionnaire for Medication (TSQM), using a national panel study of chronic disease. Health Qual Life Outcomes. 2004;2:12.

23. Chrzan K, Orme B. An overview and comparison of design strategies for choice-based conjoint analysis. Available from: https://www. sawtoothsoftware.com/download/techpap/desgncbc.pdf. Accessed March 29, 2017.

24. Orme BK. Getting Started with Conjoint Analysis: Strategies for Product Design and Pricing Research. 2nd ed. Madison, WI: Research Publishers LLC; 2010.

25. Sawtooth Software. Using our HB software: tips from the trenches. Available from: https://www.sawtoothsoftware.com/about-us/newsand-events/sawtooth-solutions/ss26-cb/1111-using-our-hb-softwaretips-from-the-trenches. Accessed March 30, 2017.

26. Sawtooth Software. The $\mathrm{CBC} / \mathrm{HB}$ system for hierarchical Bayes estimation version 5.0. Technical paper. Available from: https:// www.sawtoothsoftware.com/download/techpap/hbtech.pdf. Accessed August 28, 2017.

27. Blome C, Gosau R, Radtke MA, et al. Patient-relevant treatment goals in psoriasis. Arch Dermatol Res. 2016;308(2):69-78.

28. Mangham LJ, Hanson K, McPake B. How to do (or not to do)... Designing a discrete choice experiment for application in a low-income country. Health Policy Plan. 2009;24(2):151-158. 


\section{Supplementary material}

Table SI Comparison of patients' judgements concerning method's easiness to complete $(n=129)$

\begin{tabular}{|c|c|c|c|c|c|c|c|c|}
\hline \multirow[t]{3}{*}{ Method } & \multicolumn{2}{|c|}{$\begin{array}{l}\text { Was instruction } \\
\text { comprehensible? (yes/no) }\end{array}$} & \multicolumn{4}{|c|}{ How difficult was it to answer? } & \multicolumn{2}{|c|}{$\begin{array}{l}\text { Was it too long? } \\
\text { (yes/no) }\end{array}$} \\
\hline & \multicolumn{2}{|l|}{ Yes } & \multicolumn{4}{|c|}{0 (not at all)- 10 (very) } & \multicolumn{2}{|l|}{ Yes } \\
\hline & n (\%) & $95 \% \mathrm{Cl}$ & Mean & SD & Median & Range & n (\%) & $95 \% \mathrm{Cl}$ \\
\hline DCE & $124(96.1)$ & $91.2-98.7$ & 3.05 & 2.27 & 3 & $0-8$ & $58(45.0)$ & $36.2-54.0$ \\
\hline PNQ & $127(98.4)$ & $94.5-99.8$ & 0.84 & 1.51 & 0 & $0-9$ & $8(6.2)$ & $2.7-11.9$ \\
\hline
\end{tabular}

Abbreviations: $\mathrm{Cl}$, confidence interval; SD, standard deviation; DCE, discrete choice experiment; PNQ, Patient Needs Questionnaire.

\section{Publish your work in this journal}

Patient Preference and Adherence is an international, peer-reviewed, open access journal that focuses on the growing importance of patient preference and adherence throughout the therapeutic continuum. Patient satisfaction, acceptability, quality of life, compliance, persistence and their role in developing new therapeutic modalities and compounds to optimize clinical outcomes for existing disease states are major areas of interest for the journal. This journal has been accepted for indexing on PubMed Central. The manuscript management system is completely online and includes a very quick and fair peer-review system, which is all easy to use. Visit http://www. dovepress.com/testimonials.php to read real quotes from published authors.

\footnotetext{
Submit your manuscript here: http://www.dovepress.com/patient-preference-and-adherence-journal
} 